\title{
Sir Alan Cottrell and the Dislocation Mechanics of Fracturing
}

\author{
R.W. Armstrong \\ Center for Energetic Concepts Development, Department of Mechanical Engineering, \\ University of Maryland, College Park, MD 20742, U.S.A.
}

\begin{abstract}
Sir Alan Cottrell led the transformation of metallurgy from an observational science to analytical description. The following ditty, written for an analysis of the influence of polycrystal grain size on mechanical strength properties, could very well have been inspired by subliminal guidance from Cottrell:
\end{abstract}

The physically-weaker mortals are supported

With stronger materials, needfully, more so every day.

How so, you say - by brain power exhorted

To restrict the role that cracks and dislocations play!

The following account is an honoring contribution in recognition of the great man's leading researches on one of several materials-based topics that he led: the dislocation mechanics of fracturing.

\section{Introduction}

A previous festschrift for the $70^{\text {th }}$ birthday celebration meeting in honor of Sir Alan Cottrell [1] may be compared with related recognitions given some years previously for Professors Egon Orowan [2], Norman Petch [3], and Takeo Yokobori [4], and a few years afterward, for Professor George Irwin [5]. The fracture-related research accomplishments of Cottrell were intimately connected with those of the persons who are referenced. Cottrell made quantitative use in a real sense of the dislocations figuratively invented by Orowan [6], and are also credited to Polanyi [7] and Taylor [8]. With Norman Petch, Cottrell developed the ductile-brittle transition theory for understanding the onset at lower temperatures or higher applied loading rates of brittleness in steel and related metals $[9,10]$. Cottrell and Yokobori shared the vision of producing an understanding of fracturing on a combined microscopic and macroscopic level, this relating to encouragement from Cottrell for the founding by Yokobori of the International Congress on Fracture (ICF) [11]. Among Yokobori's earliest research articles is one on the Cottrell-Bilby theory of yielding of iron [12]. And, the later Bilby, Cottrell and Swinden [13] model of crack propagation with an attendant localized plastic zone at the crack tip provided a breakthrough example of fracturing at macroscopic dimensions, as pioneered also by George Irwin [14].

Four sub-topics among Cottrell's notable contributions to fracturing are to be covered: (1) the ductile-brittle transition temperature (dbtt); (2) the dislocation reaction mechanism for crack initiation; (3) the limiting theoretical strength of metals; and (4) the dislocation mechanisms of slip intrusions and extrusions involved in fatigue cracking. The following descriptions are intended to build onto the recent memorial articles honoring Cottrell by J.F. Knott [15], L.M. Brown [16] and D. Hull [17].

\section{Dislocation mechanics of the ductile-brittle transition temperature}


Both the Cottrell-Bilby theory of carbon-locking of dislocations for the yield point behavior in steel [18] and the Hall-Petch (H-P) dislocation pile-up model for a reciprocal square root of average grain diameter dependence of the yield and cleavage fracture stresses[19,20] entered into Cottrell obtaining an implicit description of the dbtt in the relationship [9]

$$
\mathrm{k}_{\mathrm{y}}\left(\sigma_{0 \mathrm{y}} \ell^{1 / 2}+\mathrm{k}_{\mathrm{y}}\right)=\mathrm{CG} \gamma
$$

In Eq. (1), $\mathrm{k}_{\mathrm{y}}$ is the H-P microstructural stress intensity required for breaking-free Cottrell-locked dislocation sources so as to provide transmission of plastic flow across grain boundaries, $\ell$ is the polycrystal grain diameter, $\sigma_{0 y}$ is the friction stress resistance for individual dislocation movements in slip band pile-ups, $\mathrm{G}$ is the shear modulus, $\gamma$ is the cleavage crack surface energy, and $\mathrm{C}$ is a numerical constant. Hull called attention in [17] to his measurements made with Mogford [21] showing an increase in $\sigma_{0 y}$ from neutron irradiation damage, thus raising the magnitude of the left-side of Eq. (1), and promoting brittleness. Petch obtained an explicit dependence of the dbtt on the temperature dependent component of the friction stress and on the ductile fracture stress dependent $\mathrm{H}-\mathrm{P}$ determined value of $\mathrm{k}_{\mathrm{f}}$, as [10]

$$
\mathrm{T}_{\mathrm{C}}=(1 / \beta)\left[\ln \mathrm{B}-\ln \left\{\left(\mathrm{CG} \gamma / \mathrm{k}_{\mathrm{f}}\right)-\mathrm{k}_{\mathrm{f}}\right\}-\ln \ell^{-1 / 2}\right]
$$

In Eq. (2), B is the limiting value of the temperature dependent component of the friction stress at $\mathrm{T}=0$ and $\beta$ is the exponential temperature coefficient.

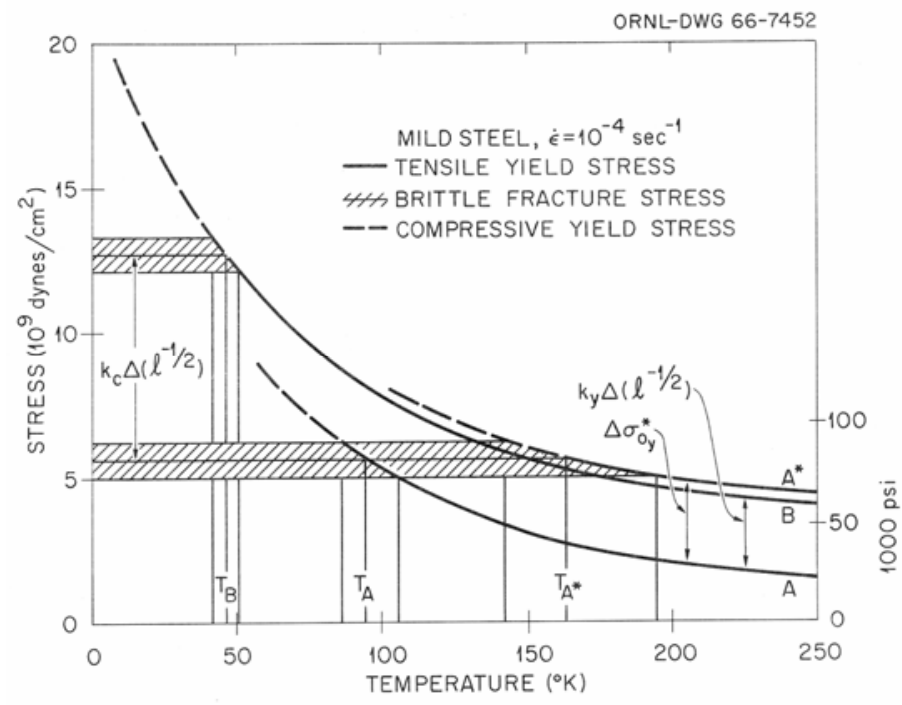

Fig. 1. Tensile ductile-brittle transition temperatures for two grain sizes, $\mathrm{A}$ of $100 \mu \mathrm{m}$ and $\mathrm{B}$ of 5 $\mu \mathrm{m}$; and, then of A altered by neutron irradiation to $\mathrm{A}^{*}$ with raised value of $\Delta \sigma_{\text {oy }}{ }^{*}$ [22].

Figure 1 provides an illustration produced at the U.S. Oak Ridge National Laboratory of the $\mathrm{dbtt}$ behavior as obtained on the basis of computed tensile test results applicable to grain size and neutron irradiation hardening [22]. In the figure, a comparison is made between the temperature dependences of the yield and cleavage fracture stresses of two annealed mild steel materials, "A" having a conventional grain size of $\sim 100 \mu \mathrm{m}$ and "B" having a grain size of $\sim 5 \mu \mathrm{m}$. In addition, the yield stress is shown to be raised after neutron irradiation hardening of steel "A", now labeled " $A$ *", but for which its cleavage stress is unchanged. As indicated in the figure, steel A has a lower dbtt because of the H-P inequality: $\mathrm{k}_{\mathrm{C}}>\mathrm{k}_{\mathrm{y}}$. And steel "A*" has an appreciably raised dbtt 
due to addition of the athermal component $\Delta \sigma_{0 \mathrm{y}}{ }^{*}$ to $\sigma_{0 \mathrm{y}}$, in the manner described by Hull and Mogford [21], thus raising the ambient temperature yield strength up to that of steel "B". The danger indicated in the figure, which was deemed important at the time, was that steels " $\mathrm{B}$ " and " $A$ *" could have the same ambient yield strengths and temperature dependencies of them while exhibiting appreciably different values of the dbtt [23].

A historical note is that Orowan had drawn attention to the condition of the yield stress being raised to the level of the cleavage fracture stress as a criterion for the onset of brittleness in steel; and, this consideration, taken together with a plastic constraint factor for the notch in a Charpy impact test [24], provided for a quantitative description of the dbtt in the same vein as described by Cottrell and Petch [25]. Wessel reported at ICF1, in Sendai, on the correlation of changes in $\mathrm{T}_{\mathrm{C}}$ associated with changes in $\sigma_{0 \mathrm{y}}$ and $\mathrm{k}_{\mathrm{y}}$ for a structural pressure vessel steel [26].

\section{The Cottrell crack-forming dislocation reaction}

In the seminal article by Cottrell on the dbtt [9], a breakthrough explanation was provided for the crystal structure dependent observation of cleavage occurring on cube-face $\{001\}$ crystal planes in steel and related body-centered cubic (bcc) metals. On the basis of the bcc slip systems having lattice parameter, "a", focus was placed on the [uvw] direction- and (hkl) planardislocation reaction for two (mixed-type) dislocation lines mutually oriented along the [010] crystal axis as:

$$
(\mathrm{a} / 2)[11-1]_{(101)}+(\mathrm{a} / 2)[-1-1-1]_{(-101)}=\mathrm{a}[00-1]_{(001)}
$$

The (001) plane is not a slip plane in the bcc lattice and under an [001] directed tensile axis, the thus-formed [00-1] edge type dislocation with line direction along [010] would anyway be a sessile dislocation. Cottrell proposed that the reacted dislocation could form a cleavage crack nucleus. Chou, Garofalo and Whitmore, followed up Cottrell's model proposal with a quantitative analysis of arrested dislocation pile-ups which would be blocked at such intersection in alpha-iron [27]. And experimentally, Hahn et al. reported observations of initiated cleavage micro-cracks at temperatures centered on the dbtt for a number of polycrystalline iron and steel materials [28]. The observations relate to the Cottrell-Petch dbtt descriptions in that it had been proposed that break-out of cracking from within individual grains was required for material failure. Antolovich and Findley have reported on a re-examination of the Cottrell model [29].

Nevertheless, the importance of Cottrell's mechanism of crack initiation also took hold for other observations of cracking in single crystal experiments. Most notably, Keh, Li and Chou applied the Cottrell model to explaining the occurrence of cleavage cracking observed on otherwise unfavorable $\{110\}$ type planes at aligned diamond pyramid hardness impressions put into rocksalt-type structure $\mathrm{MgO}(001)$ crystal surfaces [30]. Figure 2 shows a schematic view of the dislocations distributed among the indentation-activated $\{110\}<1-10>$ slip systems [31]. For this crystal geometry, the Cottrell-type reaction is specified [32] as

$$
(\mathrm{a} / 2)[10-1]_{(101)}+(\mathrm{a} / 2)[0-11]_{(011)}=(\mathrm{a} / 2)[1-10]_{(112)}
$$

The line direction of the reacted dislocation of Eq. (4) lies along the [11-1] direction. The square "picture frame" structure immediately encompassing the residual indentation is formed by volume accommodating slip on secondary $<110>\{1-10\}$ slip systems. The sub-surface interaction of dislocation pile-ups at the intersection of conjugate slip systems, for example in the second quadrant of the (001) picture frame, produces the sessile Cottrell-type dislocation reaction described in Eq. (4). 


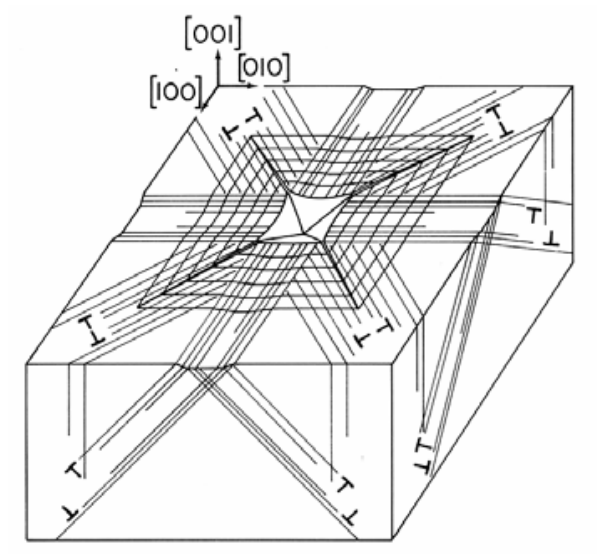

Fig. 2. The dislocation deformation pattern surrounding an aligned diamond pyramid microhardness indentation with indenter edges parallel to $<100>$ put into an (001) MgO crystal surface [31].

The sub-surface dislocation structure leading to observation on the surface of diagonal $<110>$ type cracking is illustrated in the cut-away diagram of Fig. 3. As mentioned, the cracking is on the unfavorable $\{110\}$ planes compared to normally observed $\{010)$ cleavage planes.

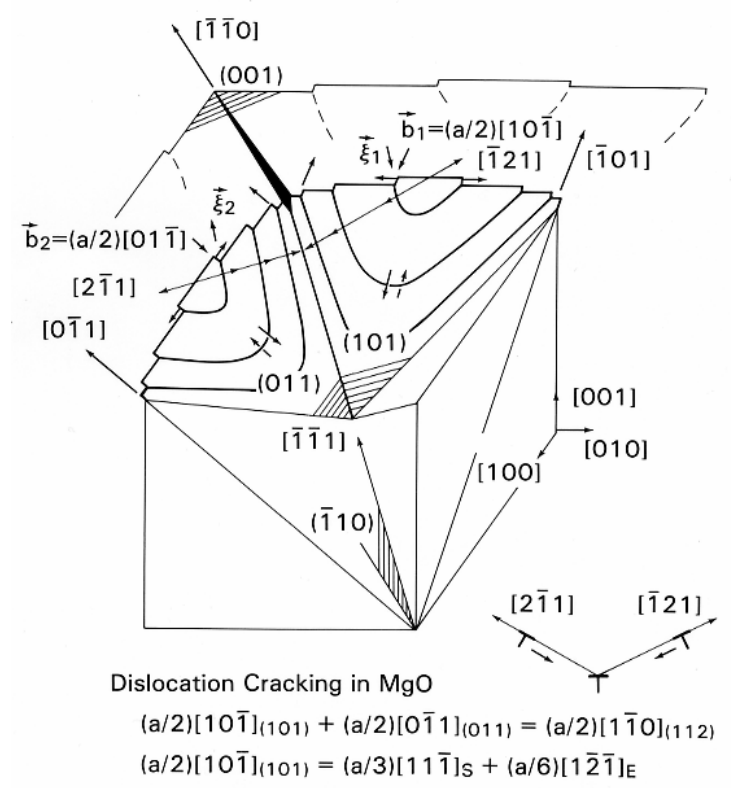

Fig. 3. Sub-surface dislocation reaction on intersecting $<110>\{1-10\}$ slip planes in $\mathrm{MgO}$ [32].

The same type of crack-forming dislocation reaction mechanism was shown to occur at aligned microhardness impressions put into the (-210) crystal surfaces of body-centered tetragonal ammonium perchlorate (AP) crystals [33]. In this case, greater plastic anisotropy was reflected in the distorted shape of the residual diamond pyramid indentation such that cracking was only initiated in the adjacent top two indentation quadrants of the indented crystal surface in which a pair of intersecting slip systems had produced greater plastic deformation --- thus giving emphasis to the Cottrell mechanism of cleavage cracking being attributed to the local intersecting slip system blockages. 


\section{The theoretical strength and brittleness}

The theoretical limiting strength of materials [34], including computations of the limiting strength to be obtained in cleaving perfect crystals [35], was of considerable research interest in the mid-1960's. The computations made in the latter reference built onto estimations of crystal strength that were described earlier in the pioneering article by Orowan [24]. Kitajima provided a report on the topic at ICF1 [36]. The situation was re-examined at the time in an important article by Kelly, Tyson and Cottrell [37] who looked in a fresh way into the stress required for separation of crystal lattice planes of potential cleavage systems. Such calculations provided a benchmark of local stress values needed at the tips of dislocation pile-ups in order to initiate cracking, for example, as described by Stroh [38]. Once such a smallest imaginable crack might be initiated, however, the question still obtains as to whether it would grow in the elastic manner described by Griffith [39] or its growth would be restricted because of initiation of plastic flow at the crack tip. As will be described subsequently, the larger scale consideration of crack growth with an associated plastic zone at the crack tip is another topic on which Cottrell and colleagues have provided an important analysis.

Figure 4 was developed based on the model consideration that the intrinsic brittleness of materials could be determined by whether a small crack would grow elastically by the (Griffith) mechanism or by initiation of plasticity at the crack tip [40]. Calculation of the ratio of the two stresses led to a suggested susceptibility factor of $(\gamma / \mathrm{Gb})^{1 / 2}$ to gage the intrinsic brittleness of metals. A tabulation of computed susceptibility factors for different metals and semi-metals demonstrated that low values of the ratio correlated reasonably well with the known propensities of the materials for cleavage. The model calculation was refined by Rice and Thomson [41] and then examined in further detail by Rice [42] who obtained the same type of agreement as originally proposed. Xu has produced a review of the subject, including further refinements of the model. In particular, Xu described a numerical evaluation of a single crystal type of dbtt controlled by the thermally-activated nucleation of dislocations at the crack tip [43].

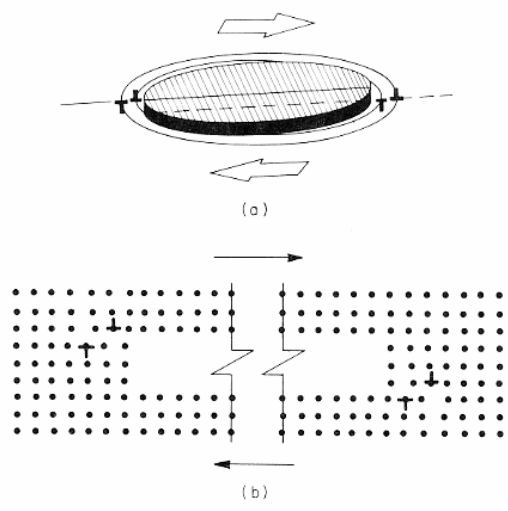

Fig. 4(a,b). Model for dislocation nucleation at the tip of a penny-shaped crack [40].

\section{The Bilby-Cottrell-Swinden model of crack growth}

Bilby, Cottrell and Swinden (BCS) had produced at micro- to macro-scopic dimensions, compared to the atomic-scale model illustration given in Fig. 4(a,b), the counterpart breakthrough description of critical crack growth with an attendant plastic zone at the crack tip [13]. Dugdale had also reported related results for a plane stress 
description of cracking in thin sheet material [44]. The BCS analysis involved use of the method of continuous distributions of dislocations to model both the elastic stress state of the crack and extent of the plastic zone (as an inverted dislocation pile-up). Unstable growth of the crack was specified for a ratio of plastic zone size, s, to crack half-length, c, at fracture stress, $\sigma_{\mathrm{F}}$, and yield stress, $\sigma_{\mathrm{y}}$, in the transcendental equation

$$
(\mathrm{s} / \mathrm{c})=\left[\sec \left(\pi \sigma_{\mathrm{F}} / 2 \sigma_{\mathrm{y}}\right)\right]-1
$$

In turn, Eq. (5) was shown to be well-approximated by the relationship [45]

$$
\sigma_{\mathrm{F}} \approx A \sigma_{\mathrm{y}}[\mathrm{s} /(\mathrm{c}+\mathrm{s})]^{1 / 2}
$$

The equation, with $\sigma_{\mathrm{y}}$ replaced by $\sigma_{\mathrm{C}}$ for crack-free material, was shown at ICF3 to describe the crack size dependence of the brittle fracture stress for several reference steel materials and for polymethylmethacrylate (PMMA) glass material. In Eq. (6), $A=(\pi / 2)$ for $(\mathrm{s} / \mathrm{c})<1.0$ and $\mathrm{A}=1.0$ for $(\mathrm{s} / \mathrm{c}) \rightarrow 1.0[46]$.

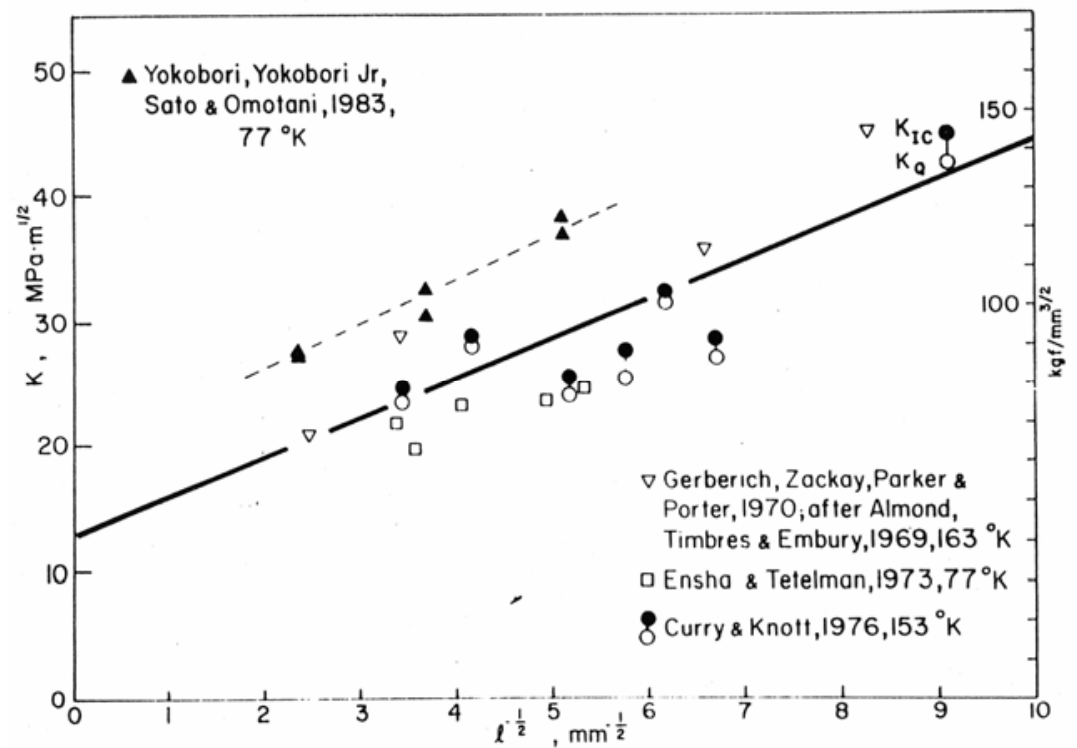

Fig. 5. Compilation of fracture mechanics stress intensity, K, values for mild steel [47].

The BCS description provided very importantly for specification of fracturing in terms of a critical crack tip opening criterion that has proved to be very useful in fracture mechanics testing [47]. But in either case of the critical stress criterion in Eq. (6) or in terms of the BCS-described crack tip opening, a same dependence on grain size and plastic zone size was obtained for the plane strain fracture mechanics stress intensity, $\mathrm{K}_{\mathrm{Ic}}$ [48]. For yielding in plane strain on a von Mises basis, a value of $K_{I c}$ was given [49] as

$$
\mathrm{K}_{\mathrm{Ic}}=(8 / 3 \pi)^{1 / 2}\left[\sigma_{0 \mathrm{C}}+\mathrm{k}_{\mathrm{C}} \ell^{-1 / 2}\right] \mathrm{s}^{1 / 2}
$$


In Eq. (7), the quantity in square brackets is Petch's relationship for the cleavage fracture stress [20]. A compilation of cleavage fracture stress measurements was reported at ICF4 [50]. At constant plastic zone size, as appears to generally obtain in engineering fracture mechanics tests, a Hall-Petch type of dependence is obtained for $\mathrm{K}_{\mathrm{Ic}}$. Figure 5 shows a compilation of results reported for mild steel and related steel materials [51-55]. An unusual aspect of Fig. 5 is that an increase in fracture toughness is shown for materials obviously exhibiting an increase in yield stress (according to the corresponding $\mathrm{H}-\mathrm{P}$ relationship for $\sigma_{\mathrm{y}}$ ). In such a fracture mechanics test, however, yielding begins at the H-P determined $\sigma_{\mathrm{y}}$ at the root of the notch and the induced plastic zone strain hardens until a higher grain size dependent value of the cleavage stress, $\sigma_{C}$, is reached [56]. Knott provided an important review of the science and engineering aspects of fracture mechanics at ICF8 [57].

\section{Slip band intrusions and extrusions}

There is grain size dependence in the fatigue strength of metals also [25] but the situation is more complex, in no small part because of the occurrence of persistent slip bands (PSBs) and their increasingly pronounced behavior under cyclic loading $[16,17$, $58]$.

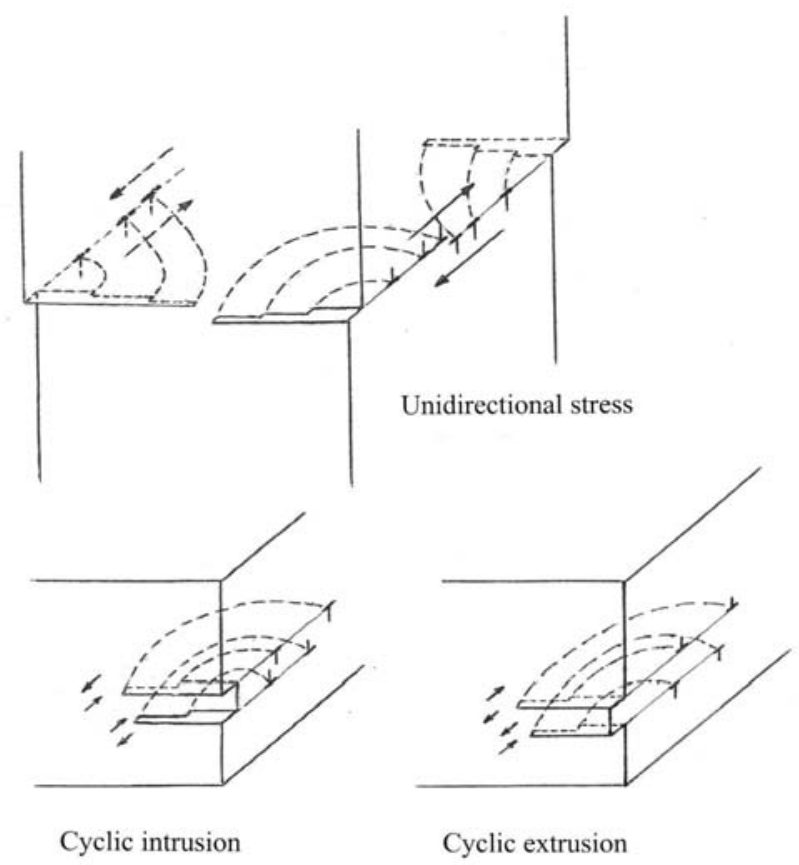

Fig. 6. Cyclically-induced slip intrusions/extrusions and internal dislocation structures.

Cottrell and Hull had produced a seminal description of surface intrusions/extrusions produced during fatigue testing [59]. Figure 6 provides a schematic illustration of the surface relief and internal dislocation structure accompanying cyclic loading [60]. Cottrell gave emphasis to the mechanical aspect of the nucleation and growth of cracking in a PSB as compared with the importance of mass transport by diffusion because of 
results obtained by Hull on copper tested at temperatures as low as $4.2 \mathrm{~K}$ [17, 61]. More recently, Coupeau, Girard and Rabier have provided excellent observations via scanning probe microscopy of slip step heights at opposing dislocation pile-ups on parallel planes and evaluated the results in terms of mutually blocking dislocation pile-ups [62]. Head had reported the first numerical calculations of such opposing dislocation pile-ups [63]. A major result from the dislocation modeled behavior was that at sufficient applied shear stress and corresponding local stress concentration, the leading dislocations passed each other and formed dipoles. The behavior is in agreement with the associated slip band structure becoming more pronounced in PSBs in part because the self-stress associated with individual dislocation dipoles decreases more rapidly with distance, of the order of $\sim(\Delta r)^{-2}$ as compared with the normal $(1 / \Delta r)$ individual dislocation behavior, and therefore leading to many more dislocations being fitted into a cyclically-defined slip band length. A sub-surface role of diffusion of atomic vacancies that has generated later research interest should be additive in the process [16].

\section{Summary}

A number of Sir Alan Cottrell's notable contributions, with colleagues too, on the dislocation mechanics of fracturing have been briefly described on four sub-topics. The listed contributions have been in the sequence of: (a) conditions for a ductile to brittle transition in steel and related metals; (b) evaluation of the theoretical limiting strength of crystals; (c) dislocation-modeled crack growth in relation to a fracture mechanics description; and, (d) geometrical aspects of the development of persistent slip band structures in fatigue. The purpose was to provide cogent examples, first, of the importance of original insights provided by Cottrell in producing a better understanding of relevant issues and, secondly, to show a positive connection with further developments already made or continuing to be made on the same subjects. In this regard, a note is added from the interview of Sir Alan at ICF4 in Waterloo, Canada, to the effect that more work needed to be done on multiple dislocation group dynamics, a topic that has been pursued in the interim time period and continues to be an important research activity [64].

\section{Acknowledgments}

It is a great pleasure for the author to thank colleagues, David Taplin and Stephen Antolovich, for encouragement to produce the present article. Involvement in the ductile to brittle transition topic began in 1958 during a post-doctoral appointment with Norman Petch, when at Leeds, and which appointment was suggested by Harold Paxton and assisted by Sir Alan. A grand remembrance was the joined recollection of the post-doctoral year and subsequent activities at morning tea with Sir Alan in 1984 at Jesus College, Cambridge. A much appreciated later sabbatical leave from the Westinghouse Research Laboratory during 1964 at the Commonwealth Scientific and Industrial Research Organization, Division of Tribophysics, spent with Walter Boas and Alan Head on a related fracturing topic [65], should also be mentioned.

\section{References}

[1]. J.A. Charles and G.C. Smith, editors, Advances in Physical Metallurgy, Sir Alan Cottrell's $70^{\text {th }}$ Birthday Meeting, Institute of Metals, London, 1990.

[2]. A.S. Argon, editor, Physics of Strength and Plasticity, M.I.T. Press, Boston, MA, 1969. 
[3]. T.N. Baker, editor, The Yield, Flow and Fracture Strength of Metals, Applied Science Publishers, London, 1983.

[4]. H. Liebowitz, editor, A Special Issue in Honor of Professor Takeo Yokobori On the Occasion of His $70^{\text {th }}$ Birthday, Engineering Fracture Mechanics, 28, [5-6], 481-816 (1987).

[5]. K.S. Chan, editor, George R. Irwin Symposium on Cleavage Fracture, Minerals, Metals, and Materials Society, Warrendale, PA, 1998.

[6]. E. Orowan, Zur Kristallplastizitaet, Zeitschrift fur Physik, 89, 605-659 (1934)

[7]. M. Polanyi, Ueber ine Art von Gitterstoerung, die einemkristal plastich machen koennte, Zeitschrift fur Physik, 89, 660-664 (1934).

[8]. G.I. Taylor, The Mechanism of Plastic Deformation of Crystals, Proceedings of the Royal Society of London A, 145, 362-404 (1934).

[9]. A.H. Cottrell, Theory of brittle fracture in steel and similar metals, Transactions of the American Institute of Mining and Metallurgical Engineers, 212, 192-203 (1958).

[10]. N.J. Petch, The ductile-brittle transition in the fracture of $\alpha$-iron, Philosophical Magazine, 3 , 1089-1127 (1958).

[11]. D.M.R. Taplin and A. Saxena, ICF: The World Academy of Structural Integrity retrospective and prospective, Strength, Fracture and Complexity, 7, 109-121 (2011).

[12]. T. Yokobori, The Cottrell-Bilby theory of yielding of iron, Physical Review, 88, 1423 (1952).

[13]. B.A. Bilby, A.H. Cottrell and K.H. Swinden, The spread of plastic yield from a notch, Proceedings of the Royal Society of London A, 272, 304-314 (1963).

[14]. G.R. Irwin, Plastic zone near a crack and fracture toughness, in: Mechanical and Metallurgical Behavior of Sheet Materials, $7^{\text {th }}$ Sagamore Ordnance Materials Research Conference, Syracuse University Research Institute, NY, 1961, pp. 63-78.

[15]. J.F. Knott, Sir Alan Cottrell: Fracture and Structural Integrity, The UK Forum for

Engineering Structural Integrity (FESI) Bulletin, 7, [1], 5 pp. (2013).

[16]. L.M. Brown, Cracks and extrusions caused by persistent slip bands, Philosophical Magazine, in print (2013).

[17]. D. Hull, A.H. Cottrell at Harwell in the mid-1950s, Philosophical Magazine,

DOI:10.1080/14786435.2013.765990 (2013).

[18] A.H. Cottrell and B.A. Bilby, Dislocation theory of yielding and strain ageing of iron, Proceedings of the Physical Society of London, A62, 49-62 (1949).

[19]. E.O. Hall, The deformation and ageing of mild steel; Discussion of results, Proceedings of the Physical Society of London, B64, 747-753 (1951).

[20]. N.J. Petch, The cleavage strength of polycrystals, Journal of the Iron and Steel Institute, 174, 25-29 (1953).

[21]. D. Hull and I.L. Mogford, Ductile Brittle Transition in Steels Irradiated with Neutrons, Philosophical Magazine, 3, 1213ff (1958).

[22]. R.W. Armstrong, Stress - Grain Size Analysis of the Ductile - Brittle Transition for Steel and Similar Metals, Radiation Metallurgy Section, Solid State Division Progress Report, Oak Ridge National Laboratory, ORNL-4020 (July 1966).

[23]. R.W. Armstrong, Influence of polycrystal grain size on several mechanical properties of materials, Metallurgical Transactions, 1, 1169-1176 (1970).

[24]. E. Orowan, Notch Brittleness and the Strength of Materials, Transactions of the Institute of Engineers and Shipbuilders of Scotland, 89, 165-215 (1946).

[25]. R.W. Armstrong, Dislocation Mechanics Description of Polycrystal Plastic Flow and Fracturing Behaviors, in: Mechanics of Materials; Fundamentals and Linkages, edited by M.A. Meyers, R.W. Armstrong and H.O.K. Kirchner, McGraw-Hill Publishers, N.Y., 1999, Chap. 10, pp. 363-398; see Fig. 10.19.

[26]. E.T. Wessel, Variations in the embrittlement of irradiated pressure vessel steels, in:

Fracture, (ICF0), Technology Press of MIT, N.Y., 1959, pp. $147 \mathrm{ff}$. 
[27]. Y.T. Chou, F. Garofalo and R.W. Whitmore, Interactions between glide dislocations in a double pile-up in $\alpha$-iron, Acta Metallurgica, 8, 480-488 (1960).

[28]. G.T. Hahn, B.L. Averbach, W.S. Owen and M. Cohen, Initiation of cleavage microcracks in polycrystalline iron and steel, in: Fracture, (ICF0), Technology Press of MIT, N.Y., 1959, pp. $91 \mathrm{ff}$.

[29] S.D. Antolovich and K.O. Findley, A new look at attractive/repulsive junctions and cleavage crack formation in bcc materials, Engineering Fracture Mechanics, 77, 201-216 (2010).

[30]. A.S. Keh, J.C.M. Li and Y.T. Chou, Cracks due to the piling-up of dislocations on two intersecting slip planes in MgO single crystals, Acta Metallurgica, 7, [10], 694-696 (1959). [31]. R.W. Armstrong and C.Cm. Wu, Lattice Misorientation and Displaced Volume for Microhardness Indentations in MgO Crystals, Journal of the American Ceramic Society, 61, [3-4], 102-106 (1978).

[32]. R.W. Armstrong and W.L. Elban, Dislocation Aspects of Plastic Flow and Cracking at Indentations in Magnesium Oxide and Cyclotrimethylenetrinitramine Explosive Crystals, in: Microindentation Techniques in Materials Science and Engineering, edited by P.J. Blau and B.R. Lawn, ASTM STP 889, American Society for Testing and Materials, 1986, pp. 109-126.

[33]. W.L. Elban and R.W. Armstrong, Plastic Anisotropy and Cracking at Hardness Impressions in Single Crystal Ammonium Perchlorate, Acta Materialia, 46, [17], 6041-6052 (1998).

[34]. A. Kelly, Strong Solids, Clarendon Press, Oxford, U.K., 1966.

[35]. Theoretical Strength of Materials, U.S. National Academy of Science, Materials Advisory

Board, Publication MAB-221-M (1966).

[36]. K. Kitajima, On the mechanism of cleavage of crystals. In: International Conference on

Fracture (ICF1), Sendai (1965).

[37]. A. Kelly, W.R. Tyson and A.H. Cottrell, Ductile and brittle crystals, Philosophical. Magazine, 15, 567-586 (1967).

[38]. A.N. Stroh, The Formation of Cracks as a Result of Plastic Flow, Proceedings of the Royal Society of London A, 223, 404-414 (1954).

[39]. A.A. Griffith, The Phenomena of Rupture and Flow in Solids, Philosophical Transactions of the Royal Society of London A, 221, 163-198 (1920-21).

[40]. R.W. Armstrong, Cleavage crack propagation within crystals by the Griffith mechanism versus a dislocation mechanism, Materials Science and Engineering, 1, 250-254 (1966).

[41]. J.R. Rice and R. Thomson, Ductile versus Brittle Behaviour of Crystals, Philosophical Magazine, 29, 73-97 (1974).

[42]. J.R. Rice, Dislocation nucleation from a crack tip: An analysis based on the Peierls concept, Journal of the Mechanics and Physics of Solids, 40, 239-271 (1992).

[43]. G. Xu, Dislocation Nucleation from Crack Tips and Brittle to Ductile Transitions in Cleavage Fracture, in: Dislocations in Solids, edited by F.R.N. Nabarro and J.P. Hirth, Elsevier B.V., Oxford, 2004, 12, Chap. 65, pp. 81-145.

[44]. D.S. Dugdale, Yielding of steel sheets containing slits, Journal of the Mechanics and Physics of Solids, 8, 100ff (1960).

[45]. R.W. Armstrong, Crack size and grain size dependence of the brittle fracture stress, in:

Dritte Iinternationale Tagung uber den Bruch (ICF3), edited by A Kochendorfer, Verein

Deutscher Eisenhuttenleute, Duesseldorf, 1973, Paper III-421, 6 pp.

[46]. R.W. Armstrong and O. Cazacu, Indentation fracture mechanics toughness dependence on grain size and crack size: Application to alumina and WC-Co, International Journal of Refractory Metals and Hard Materials, 24, 129-134 (2006); see Fig. 1.

[47]. B.A. Bilby, Dislocations and Cracks, Dritte Internationale Tagung den Bruch (ICF3), edited by A. Kochendorfer, Verein Deutscher Eisenhuttenleute, Duesseldorf, 1973, Paper PLI-III.

[48]. R.W. Armstrong, The (cleavage) strength of pre-cracked polycrystals, Engineering Fracture Mechanics, 28, [5-6], 529-538 (1987). 
[49]. R.W. Armstrong, Dislocation viscoplasticity aspects of material fracturing, Engineering Fracture Mechanics, 77, 1348-1359 (2010).

[50]. R.W. Armstrong, Grain Size: The Fabric of Brittle Fracture of Polycrystals, in: Fracture 1977, Fourth Internal Conference on Fracture (ICF4), edited by D.M.R. Taplin, University of Waterloo, Canada, 1977, 4, pp. 83-96.

[51]. E.A. Almond, D.H. Timbres and J.D. Embury, The influence of second phase particles on brittle fracture, in: Fracture 1969; The $2^{\text {nd }}$ International Conference of Fracture (ICF2), Chapman and Hall Limited, London, 1969, pp. 253ff.

[52]. W.W. Gerberich, V.F. Zackay, E.R. Parker and D. Porter, The role of grain boundaries on crack growth, in: Ultra-fine Grain Metals, edited by J.J. Burke and V.V. Weiss, Syracuse University Press, NY, 1970, pp. 259-293.

[53]. S. Ensha and A.S. Tetelman, A quantitative model for the temperature, strain rate and grain size dependence of fracture toughness of low alloy steel, Dritte Internationale Tagung uber den

Bruch (ICF3), edited by A. Kochendorfer, Verein Deutscher Eisenhuttenleute, Duesseldorf, 1973, Paper I-331.

[54]. D.A. Curry and J.F. Knott, The relationship between fracture toughness and microstructure in the cleavage fracture of mild steel, Metal Science, 10, $1 \mathrm{ff}$ (1976).

[55]. T. Yokobori, A.T. Yokobori, Jr., K. Sato and M. Omotani, The effects of ferrite grain size on fracture of low carbon steel under mixed modes I and II, Engineering Fracture Mechanics, 17, 75-85 (1983).

[56]. N.J. Petch and R.W. Armstrong, Work hardening in cleavage fracture toughness, Acta Metallurgica, 37, [8], 2279-2285 (1989).

[57] J.F. Knott, The Science and Engineering of Fracture, in: Advances in Fracture Resistance and Structural Integrity (ICF8), Pergamon Press, Oxford, 1994, pp. 13-49.

[58]. H. Mughrabi, Cyclic slip irreversibilities and the evolution of fatigue damage, Metallurgical and Materials Transactions A, 40A, 1257-1279 (2009).

[59]. A.H. Cottrell and D. Hull, Extrusion and intrusion by cyclic slip in copper, Proceedings of the Royal Society of London A, 242, 211-213 (1957).

[60]. S.D. Antolovich and R.W. Armstrong, Plastic strain localizations in metals: Origins and Consequences, Progress in Materials Science, in print (2013).

[61]. D. Hull, Surface structure of slip bands in copper fatigued at $293 \mathrm{~K}, 90 \mathrm{~K}$, and $4.2 \mathrm{~K}$, Journal of the Institute of Metals, 86, [9], 425-430 (1958).

[62]. C. Coupeau, J.-C. Girard and J. Rabier, Scanning Probe Microscopy and Dislocations, in: Dislocations in Solids, edited by F.R.N. Nabarro and J.P. Hirth, Elsevier B.V., Oxford, 2004, 12, Chap. 67, pp. 273-338; see Figs. 46-48.

[63]. A.K. Head, The Position of Dislocations in Arrays, Philosophical Magazine, 4, 295-302 (1959).

[64]. J.F. Knott and D.M.R. Taplin, Recorded Interview with Sir Alan Cottrell, Fracture 1977, Fourth International Conference on Fracture (ICF4), Waterloo, Canada, in: Advances in Research on Strength and Fracture of Materials, Pergamon Press, Oxford, 1977.

[65]. R.W. Armstrong and A.K. Head, Dislocation queueing and fracture in an elastically anisotropic material, Acta Metallurgica, 13, 759-764 (1965). 